\title{
Responsivity of porous silicon for blue visible light with high sensitivity
}

\author{
Massar A. Kaood and Iftikhar M. Ali \\ Department of Physics, College of Science, University of Baghdad \\ E-mail: iftikhariq@gmail.com
}

\begin{abstract}
In this work, porous silicon (PS) are fabricated using electrochemical etching (ECE) process for p-type crystalline silicon (c-Si) wafers of (100) orientation. The structural, morphological and electrical properties of PS synthesized at etching current density of $(10,20,30) \mathrm{mA} / \mathrm{cm}^{2}$ at constant etching time $10 \mathrm{~min}$ are studied. From X-ray diffraction (XRD) measurement, the value of FWHM is in general decreases with increasing current density for p-type porous silicon (p-PS). Atomic force microscope (AFM) showed that for p-PS the average pore diameter decreases at $20 \mathrm{~mA}$. Porous silicon which formed on silicon will be a junction so I-V characteristics have been studied in the dark to calculate ideality factor (n), and saturation current $\left(I_{s}\right)$ for these junctions. These junctions are used in photo sensors applications, where the photo sensors have been examined at blue light region. Sensitivity, rise and fall times have been calculated for this wavelength, the maximum value for sensitivity is $(3797.6 \%)$ at etching current density $10 \mathrm{~mA} / \mathrm{cm}^{2}$ under blue light illumination at zero bias voltage.
\end{abstract}

Key words

Porous silicon, photo sensor, responsivity, sensitivity.

\section{Article info.}

Received: Oct. 2017

Accepted: Dec. 2017

Published: Jun. 2018

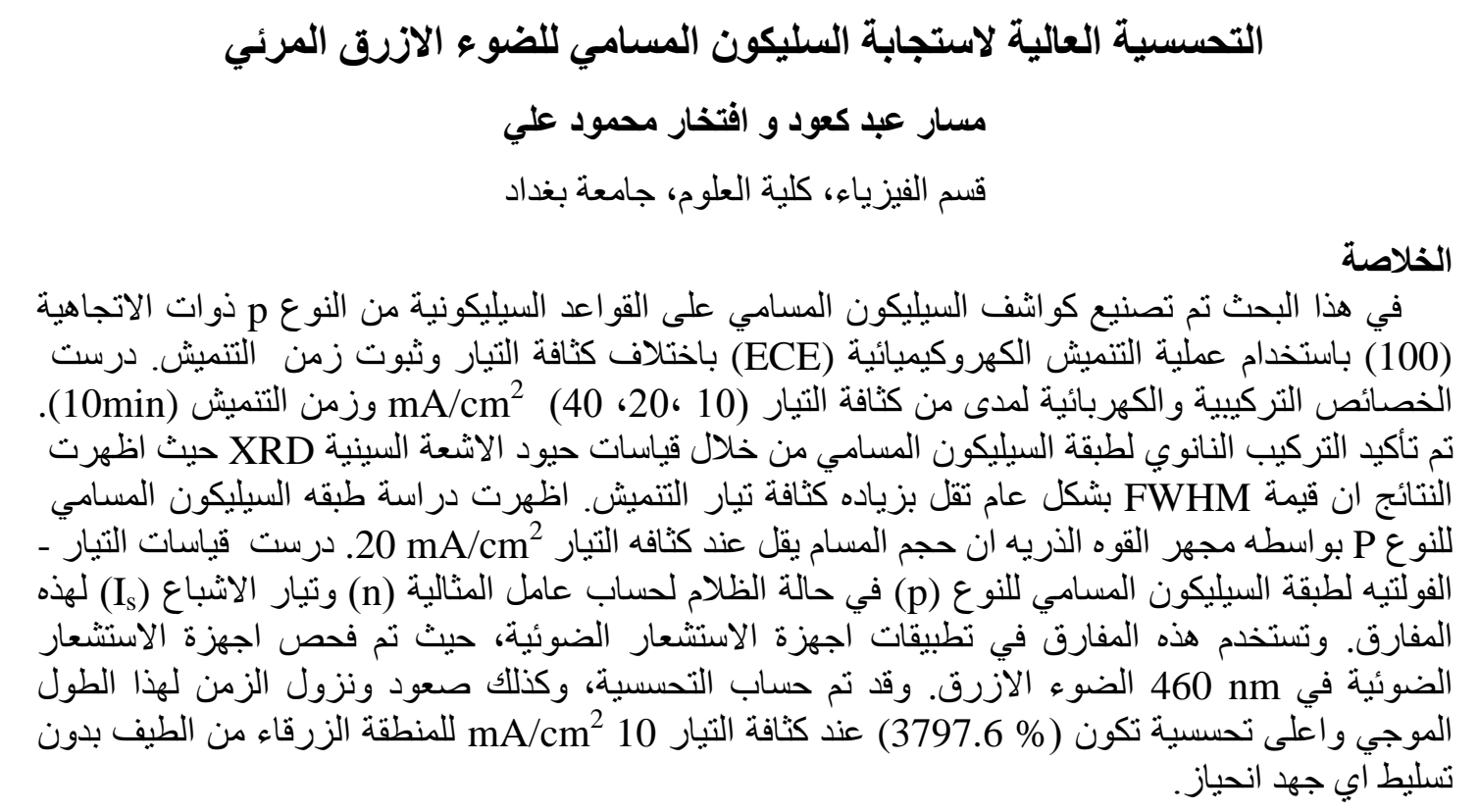

\section{Introduction}

Porous silicon is an interesting and versatile optical material that is fabricated by electrochemical etching of silicon. Porous silicon technologies have many applications in semiconductor technology [1]. In the early $1990 \mathrm{~s}$, the discovery of room 
temperature photoluminescence from porous silicon by Canham who started a renewed interest in this material [2]. Since then, porous silicon has been developed as a means of increasing the functionality of silicon technology. The physical properties of porous silicon are fundamentally determined by the shape, diameter of pores, porosity, and the thickness of the formed porous layer. Depending on the etching parameters, for example current density, HF concentration, or substrate doping type and level, the physical properties of PS can be varied [3].

Photoconductivity (PC) is defined as electrical conductivity resulting from photo-induced electron excitations in which light is absorbed. In semiconductors, photoconductivity arises due to interaction of photons with bound electrons of lattice atoms that leads to photo-generation of electron-hole pairs after absorption of photons which increases carrier density and conductivity of material [4].

Since last decade the photoconductive properties of the inorganic nanoparticles have become subject of intensive study. Not only because of fundamental interests in the nature of the electronic excitations but also due to their applications in wide range of optical and electronic devices [5].

PC is an important tool to study the properties of semiconducting materials such as the nature of photo-excitation and recombination processes. The conductivity of material depends upon the carrier density, carrier lifetime and complex process of carrier generation, trapping, and recombination [6]. It is also a function of temperature, applied field, intensity of light and energy of radiation [7]. Extensive study of photoconductivity has been made in nanoparticles, thin film, nanorods, nanowires and mixed lattice $[8,9]$ for different parameters. A good photoconductive device requires not only efficient charge separation but also efficient transport of charge carriers to electrode [10].

In this work, p-PS have been used as photo sensor which is sensitive to light in the visible range which proves the success formation for porous process.

\section{Experimental procedure}

PS layer was prepared by electrochemical anodic etching of $\mathrm{Si}$ wafer:B (p-type)(100) oriented silicon substrate with a resistivity $0.01-$ $0.02 \Omega . c m$. Before electrochemical etching process, the silicon wafers are cleaned with a solution HF: ethanol with a volume ratio 1:10 for a period of about 1 minutes. Thin film layer of $\mathrm{Ag}$ has been deposited on the wafers by electrodeposition method where wafers are immersed into a solution of $0.1 \mathrm{M}$ silver nitrate solution that dissolved in $100 \mathrm{ml}$ of distilled water. Silicon connected to the circuit with power supply in which the face of silicon opposite to platinum pole that connected to the positive end of the power supply with $3 \mathrm{~V}$ that supplies current equals to $20 \mathrm{~mA}$ for 5 minutes. Silicon connected to the negative end of power supply, this Ag atoms work as a catalyst making the etching process easier. Then silicon wafers are cut into small pieces $\left(1.3 \times 1.3 \mathrm{~cm}^{2}\right)$. The electrochemical etching process has been carried out at room temperature using Teflon materials which are adopted to form the mainbody of hydrofluoric acid (HF) based electrolyte container. A mixture containing HF (40\%), ethanol of (99 \%) and hydrogen peroxide (HF: ethanol: $\mathrm{H}_{2} \mathrm{O}_{2}=1: 4: 1$ volume ratio) were used as the etching solvent for all PS samples. $\mathrm{H}_{2} \mathrm{O}_{2}$ was added to the (HF) solution in order to improve the wettability of the acid and to allow 
diffusion for the $\mathrm{F}$ ions into pores and to improve the PS layer uniformity by removing the hydrogen bubbles and helps to moisten silicon surface and improve reproducibility [11]. The anodization is done at room temperature under constant time of 10 minutes for etching current densities $(10,20,40) \mathrm{mA} / \mathrm{cm}^{2}$, as shown in Fig.1.

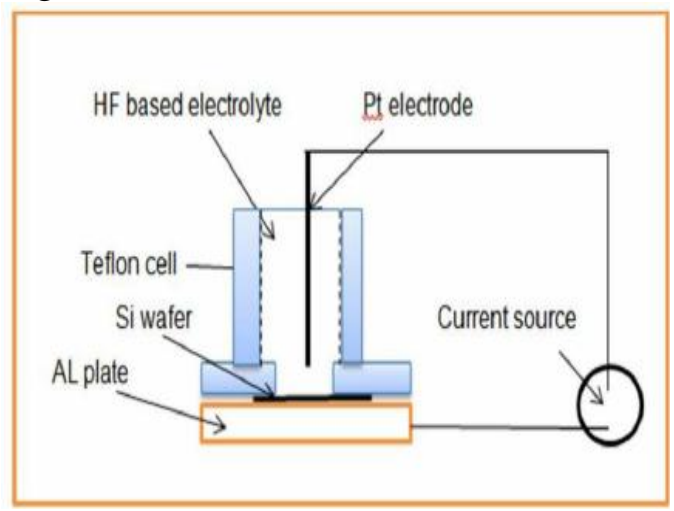

Fig.1: The electrochemical etching setup.

\section{Result and discussion}

\section{X-Ray diffraction results}

Fig. 2 shows the x-ray diffraction of porous silicon p-type (100) direction at different current densities (10, 20, 40) $\mathrm{mA} / \mathrm{cm}^{2}$ for constant etching time of $10 \mathrm{~min}$. XRD patterns show the formation of porous silicon where the strong peak of $\mathrm{Si}$ is observed at $2 \theta=68.002^{\circ}$ to p-type for (100) direction. The broadening in this peak proves the nanosize effect where the large value of FWHM (2.5230) at $10 \mathrm{~mA} / \mathrm{cm}^{2}$ may be due to the small crystallites that illustrate there is a control on the nanosize of porous layer. The formation of porous layer results in lattice expansion or the strain that caused by the effect of nanostructure that make small shift in the peak positions [12]. It is observed from Table 1 that the value of FWHM is in general decreases with increasing current density. The crystallite size is calculated by using Debye Scherrer formula in Eq. (1):

$\mathrm{D}=\mathrm{K} \lambda / \beta \cos \theta$

where $\lambda$ is the $\mathrm{X}$-ray wavelength

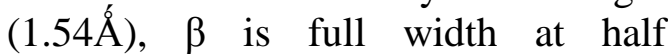
maximum (FWHM), $\theta$ is Bragg's angle, $\mathrm{K}$ is the Scherrer's constant which was ranged from (0.9 to 1) depends on geometry of structure. It is clear from these calculations that there is an increase in crystallite size from 3.8 to $39.6 \mathrm{~nm}$ for highest peak for $\mathrm{p}$ type silicon, other parameters in the table are calculating corresponding to the highest peak in Fig. 2. Also this figure shows that there is $\mathrm{SiO}_{2}$ phase which proves the formation of porous silicon.

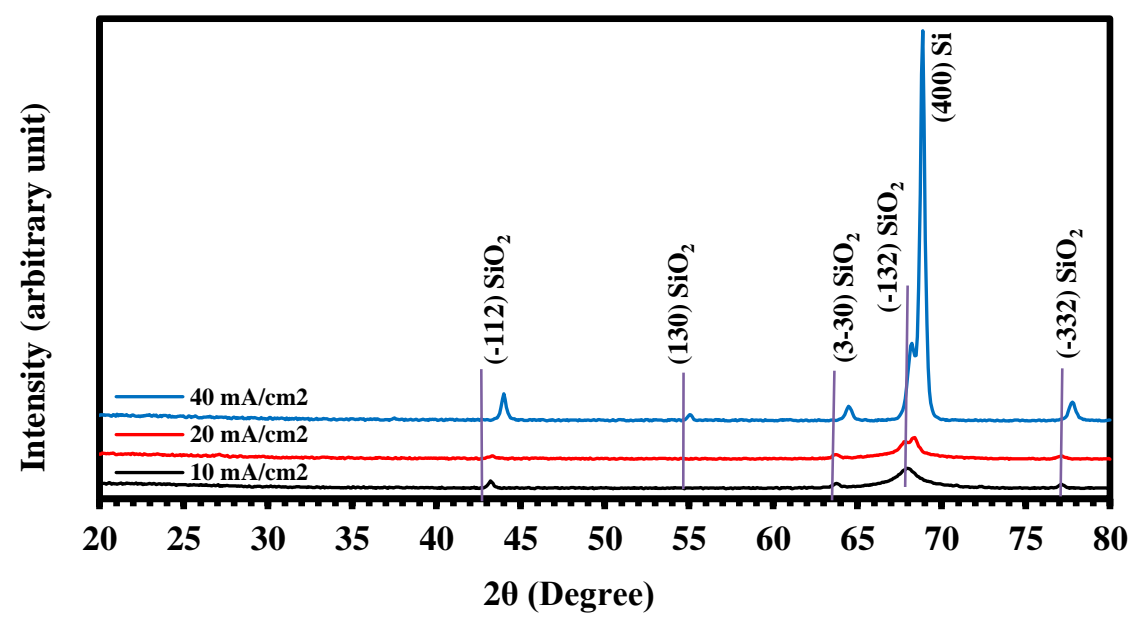

Fig.2: $X$-ray diffraction of $p$-PS prepared at current densities $(10,20,40) \mathrm{Ma} / \mathrm{cm}^{2}$ and 10 min etching time. 
Table 1: Structural parameters: 20, $d_{h k l}$, $(h k l), F W H M$ and crystallite size (D) of p-PS at current densities (10, 20 and 40) $\mathrm{mA} / \mathrm{cm}^{2}$ at 10 min etching time.

\begin{tabular}{|c|c|c|c|c|c|c|c|c|}
\hline I (Ma) & $2 \theta$ (Deg.) & $\begin{array}{c}\text { FWHM } \\
\text { (Deg.) }\end{array}$ & $\begin{array}{r}\mathbf{d}_{\text {hkl }} \\
\operatorname{Exp} .(\AA)\end{array}$ & $\begin{array}{c}\mathbf{D} \\
(\mathbf{n m})\end{array}$ & hkl & $\begin{array}{r}\mathbf{d}_{\text {hkl }} \\
\text { Std.(A) }(\mathbf{A})\end{array}$ & Phase & Card No. \\
\hline 10 & 68.0020 & 2.5230 & 1.3781 & 3.8 & (400) & 1.3577 & Cub. Si & $96-410-4918$ \\
\hline 20 & 67.8934 & 1.5420 & 1.3794 & 6.2 & $(400)$ & 1.3577 & Cub. Si & $96-410-4918$ \\
\hline 40 & 68.2000 & 0.5000 & 1.3740 & 19.2 & (400) & 1.3577 & Cub. Si & 96-410-4918 \\
\hline
\end{tabular}

2. Atomic Force Microscopy (AFM) analysis results

The morphological properties of $\mathrm{p}$ PS samples prepared with different current densities (10, 20 and 40) $\mathrm{mA} / \mathrm{cm}^{2}$ at $10 \mathrm{~min}$ etching time are shown in Fig.3. Pores are observed on the surface of the layer to be distributed uniformly. The pores have sphere-like shape and the porous layers have sponge-like appearance. As shown in Table 2 the average pore diameter decreases at $20 \mathrm{~mA}$ because the effect of chemical dissolution and current density increase and this make reducing in the wall separated between the pores which grow preferentially towards the source of positive carriers (holes), which are involved in the electrochemical dissolution reaction [13].
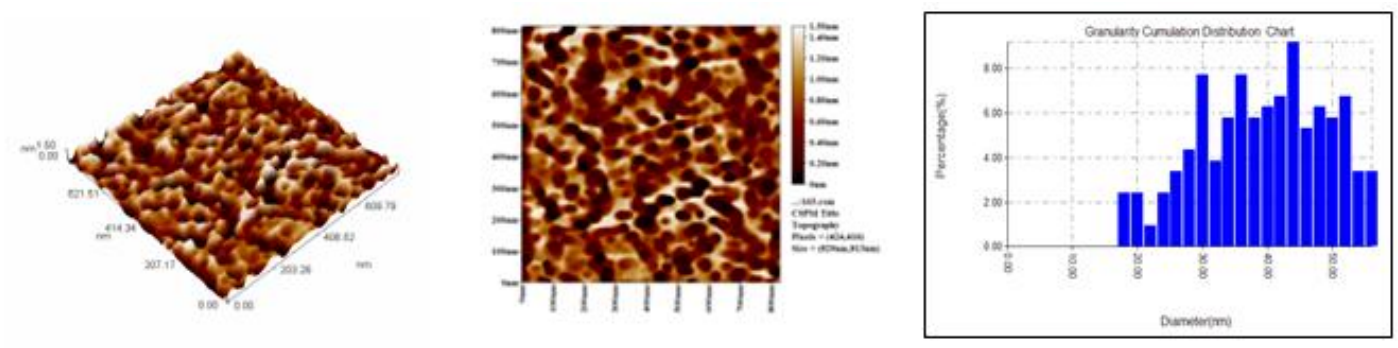

(a)
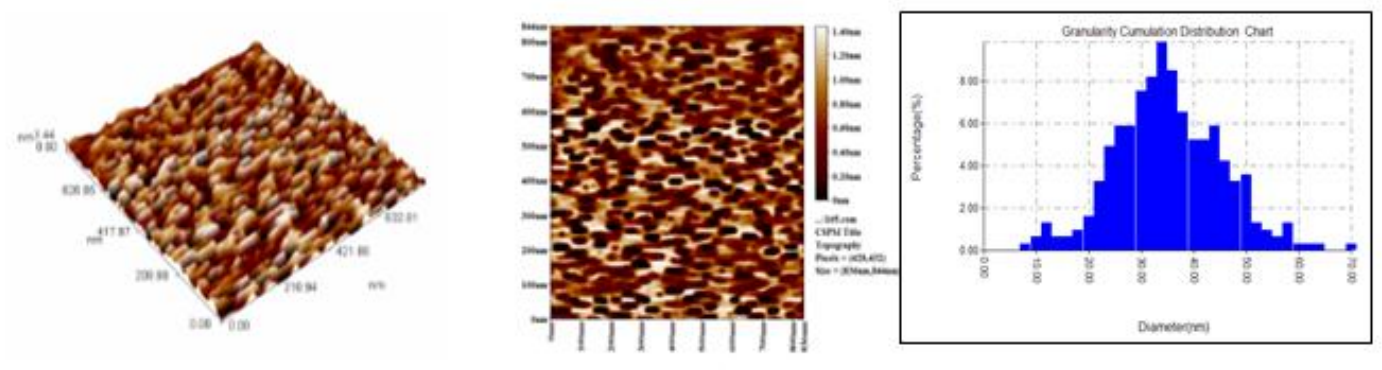

(b)
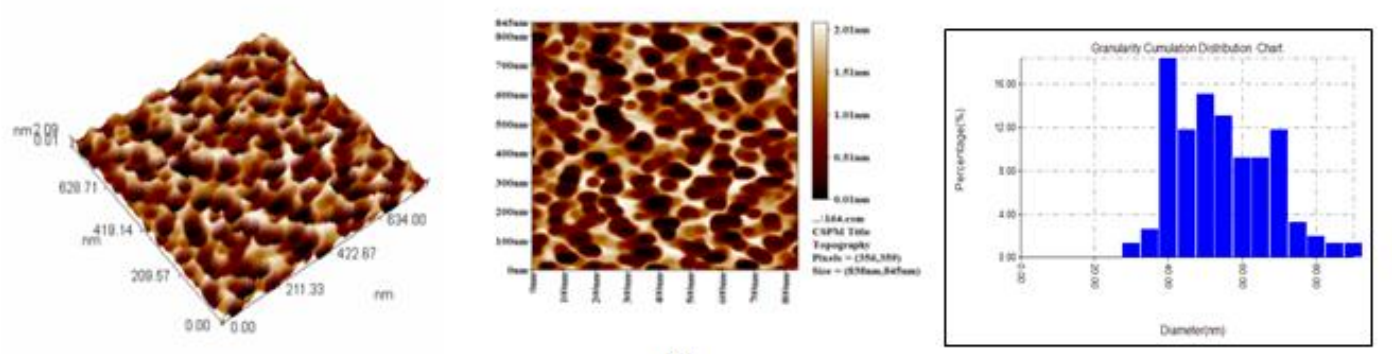

(c)

Fig.3: 2D, 3D AFM images and size distribution diagrams of meso - porous silicon (p-type) prepared at different current densities; (a) 10, (b) 20, (c) $40 \mathrm{~mA} / \mathrm{cm}^{2}$. 
Table 2: The calculated morphology characteristics of p-PS samples prepared at different etching current densities.

\begin{tabular}{|c|c|c|c|c|}
\hline $\begin{array}{c}\text { Current density } \\
\left(\mathbf{m A} / \mathbf{c m}^{\mathbf{2}}\right)\end{array}$ & $\begin{array}{c}\text { Roughness } \\
\text { Average } \\
(\mathbf{n m})\end{array}$ & $\begin{array}{c}\text { r.m.s } \\
\text { roughness } \\
(\mathbf{n m})\end{array}$ & $\begin{array}{c}\text { Average Pore } \\
\text { Diameter (nm) }\end{array}$ & $\begin{array}{c}\text { Average Pore } \\
\text { Height (nm) }\end{array}$ \\
\hline 10 & 0.322 & 0.379 & 38.31 & 1.50 \\
\hline 20 & 0.344 & 0.399 & 34.19 & 1.44 \\
\hline 40 & 0.252 & 0.298 & 54.43 & 1.21 \\
\hline
\end{tabular}

3. Fourier- transform infrared (FTIR)

Fig. 4 shows, the FTIR spectra measured for porous silicon at current density $\left(20 \mathrm{~mA} / \mathrm{cm}^{2}\right)$ and etching time (10 min), the peaks at around (486.762) $\mathrm{cm}^{-1} \mathrm{Si}-\mathrm{O}$ stretching in Si-O-Si mode, which are dependent on the oxidation degree of PSi. The transmittance peak at $(1046.94) \mathrm{cm}^{-1}$ $\mathrm{Si}-\mathrm{O}$ stretching in $\mathrm{O}-\mathrm{Si}-\mathrm{O}$ and $\mathrm{C}-\mathrm{Si}-\mathrm{O}$ [14]. While the peak at (1615.03) $\mathrm{CH}_{2}$ Wagging $\mathrm{C}=\mathrm{C}$ stretch mode and a strong broad band is observed at (3407.98) $\mathrm{cm}^{-1} \mathrm{O}-\mathrm{H}$ mode.

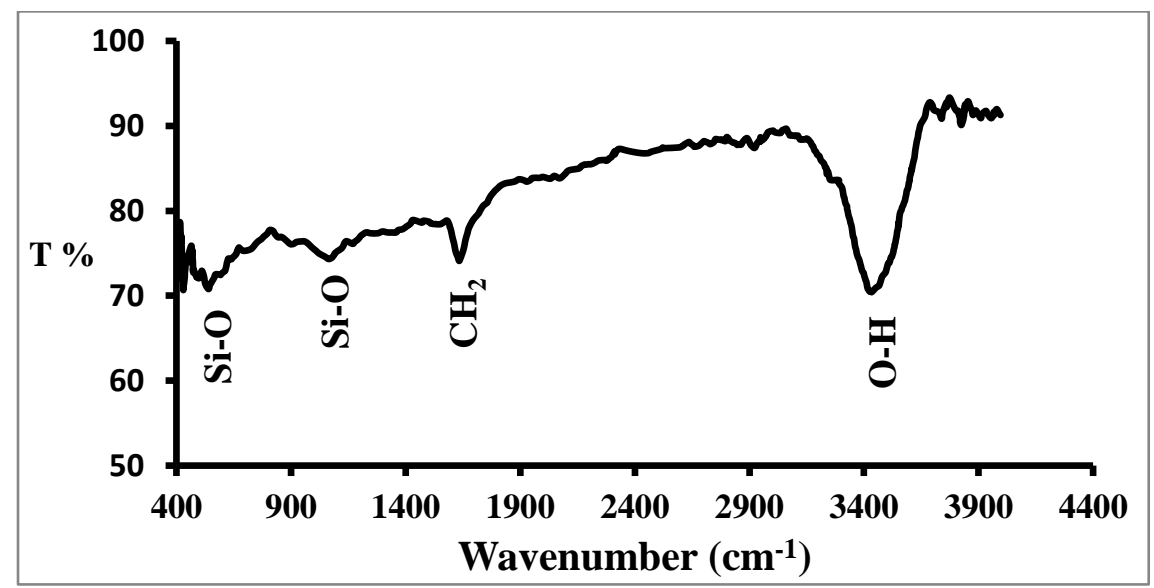

Fig.4: FTIR transmittance spectrum for PSi (n-type) at $\left(20 \mathrm{~mA} / \mathrm{cm}^{2}\right)$ and etching time (10min).

Table 3: Wavenumber positions and bonds of the transmittance peaks observed in several PS samples by Fourier transform infrared absorption FTIR measurements.

\begin{tabular}{|c|c|}
\hline \multicolumn{2}{|c|}{ p-PS } \\
\hline Peak position $\left(\mathrm{cm}^{-1}\right)$ & Bound \\
\hline 486.762 & Si-O stretching in Si-O-Si \\
\hline 1046.94 & Si-O stretching in O-Si-O and C-Si-O \\
\hline 1615.03 & $\mathrm{CH}_{2}$ Wagging C=C stretch \\
\hline 3407.98 & O-H \\
\hline
\end{tabular}




\section{I-V characteristics for p-PS in the dark}

The dark I-V characteristics at different current densities of $(10,20$, 40) $\mathrm{mA} / \mathrm{cm}^{2}$ at constant etching time of
$10 \mathrm{~min}$ for the p-PS hetero junction. It is obvious that the curve has a nonlinear behavior this indicates that the electrical contact is not ohmic as shown in Fig. 5.

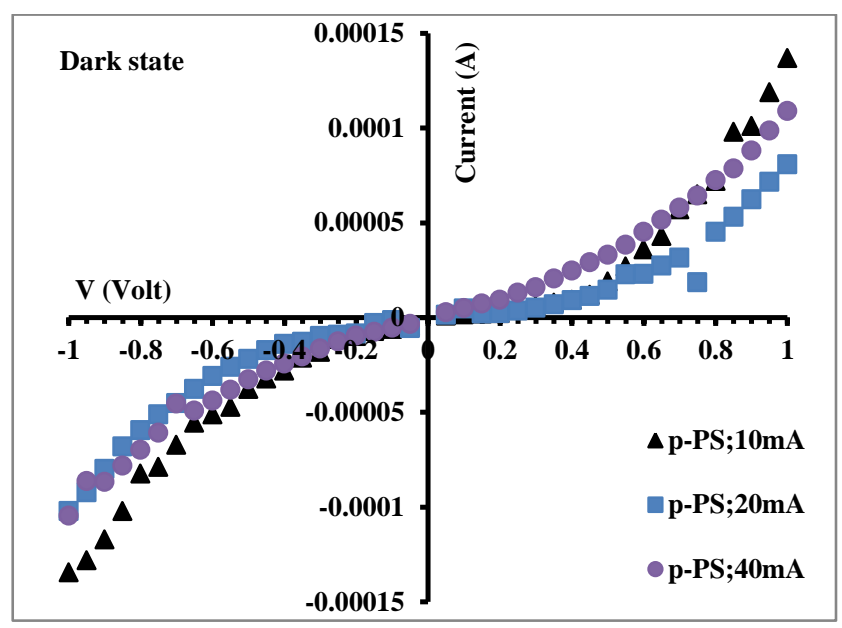

Fig. 5: I-V characteristics in the dark for p-PS.

In general the forward dark current is generated due to the flow of majority carriers and the applied voltage inject majority carriers which leads to decrease the value of built-in potential, and decrease the width of the depletion layer. Then the majority and minority carrier concentration is higher than the intrinsic carrier concentration $\left(\mathrm{n}_{\mathrm{i}}{ }^{2}<\mathrm{np}\right)$ which leads to generate recombination current at the low voltage region (00.3) $\mathrm{V}$ because that the excitation electrons from V.B to C.B will recombine with the holes which found at the V.B, and this is observed by little increase in recombination current at low voltage region. The tunneling current has been represented at the high voltage region $(>0.3 \mathrm{~V})$. After that there is a fast exponential increase in the current magnitude with increasing the voltage and this is called diffusion current. Also the reverse bias current which also contain two regions, in the first region (low voltages $<0.3 \mathrm{~V}$ ) the current slightly increases with increasing the applied voltage, and the generation current dominates, while at the high voltage region $(>0.3 \mathrm{~V})$, the diffusion current dominates [15]. The value of saturation current $I_{s}$, ideality factor $\mathrm{n}$ and are calculated from Eq. (2) as shown in Fig. 6 and their values are tabulated in Table 4:

$\mathrm{n}=\left(\mathrm{q} / \mathrm{k}_{\mathrm{B}} \mathrm{T}\right)\left(\mathrm{V} / \mathrm{Ln}\left(\mathrm{I}_{\mathrm{F}} / \mathrm{I}_{\mathrm{s}}\right)\right)$

where $V$ and $I_{f}$ are the forward bias voltage and forward current respectively, $\mathrm{q}$ is electronic charge, $\mathrm{k}_{\mathrm{B}}$ Boltzman constant and $\mathrm{T}$ temperature which is $300 \mathrm{~K}$. 


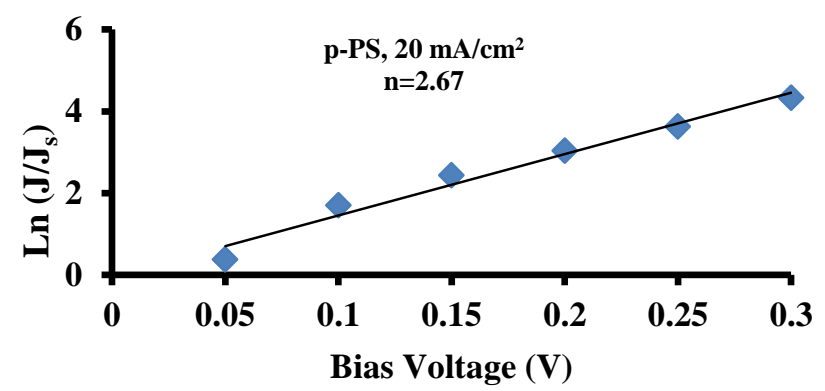

Fig. 6: Variation of $\operatorname{Ln}\left(J / J_{s}\right)$ vs. bias voltage to extract ideality factor.

Table4: $I_{s}$ and $n$ for p-PS at different etching current densities in dark.

\begin{tabular}{|c|c|c|}
\hline $\begin{array}{c}\text { Etching current } \\
\text { density }\left(\mathbf{m A} \mathbf{A} \mathbf{c m}^{\mathbf{2}}\right)\end{array}$ & $\mathbf{I}_{\mathbf{s}} \mathbf{x 1 0 ^ { - \mathbf { 6 } } \mathbf { A }}$ & $\mathbf{n}$ \\
\hline 10 & 0.19 & 5.94 \\
\hline 20 & 0.25 & 2.67 \\
\hline 40 & 0.85 & 5.12 \\
\hline
\end{tabular}

The current-voltage measurements intensity $287.65 \mathrm{~mW} / \mathrm{cm}^{2}$ from have been done under light with Halogen lamp, as shown in Fig.7.

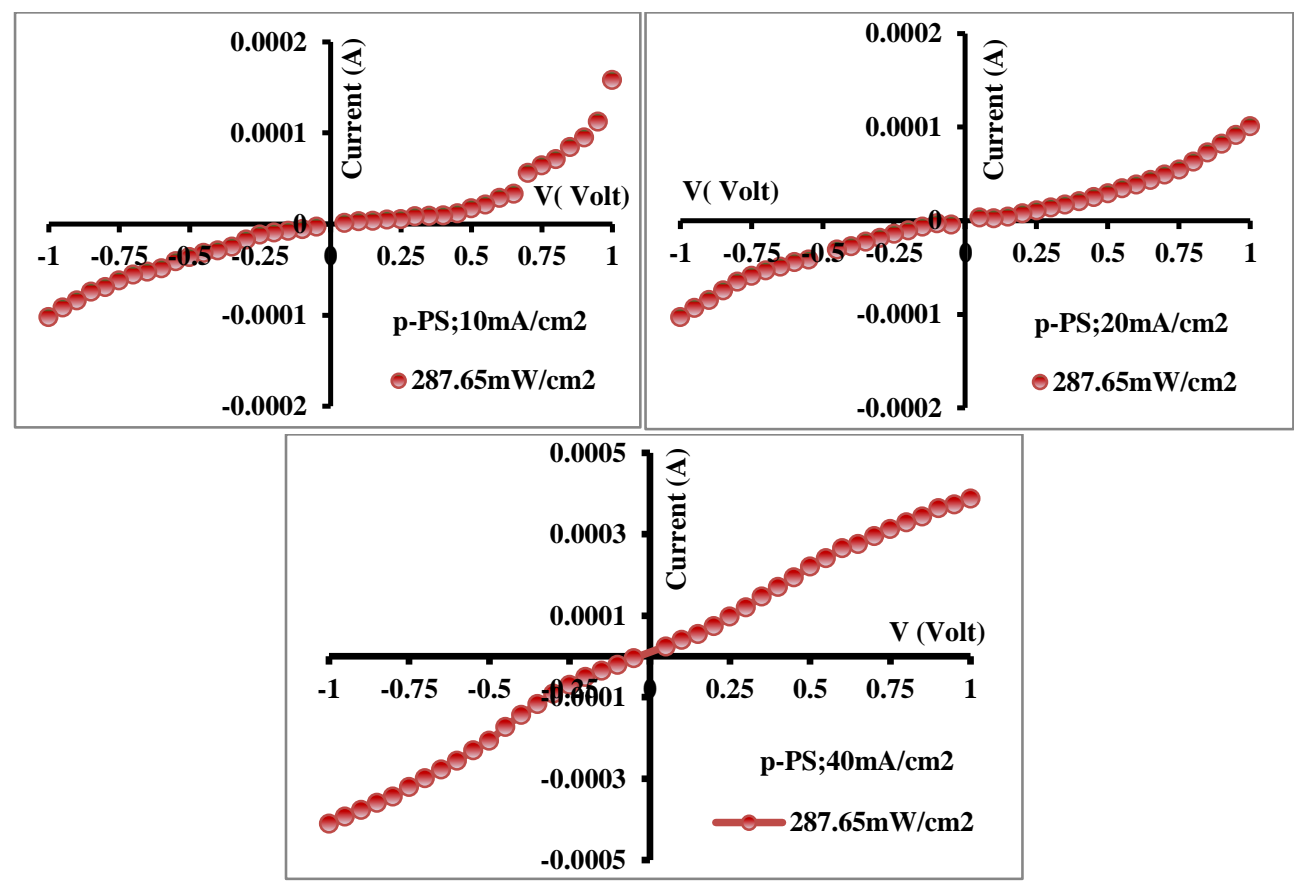

Fig.7: I-V characteristics under white light for p-PS at current densities (10, 20 and 40) $\mathrm{mA} / \mathrm{cm}^{2}$.

\section{Responsivity $\mathbf{R}_{\lambda}$ for $\mathbf{p - P S}$}

The light responsivity of the devices is measured in the wavelength range of (200-900) nm under zero bias voltage. Fig. 8 shows the measured maximum values of responsivity at the labeled wavelengths for anodization current densities of $(10,20$ and 40) $\mathrm{mA} / \mathrm{cm}^{2}$. In general, at blue light region there is maximum responsivity obtained for our devices. 

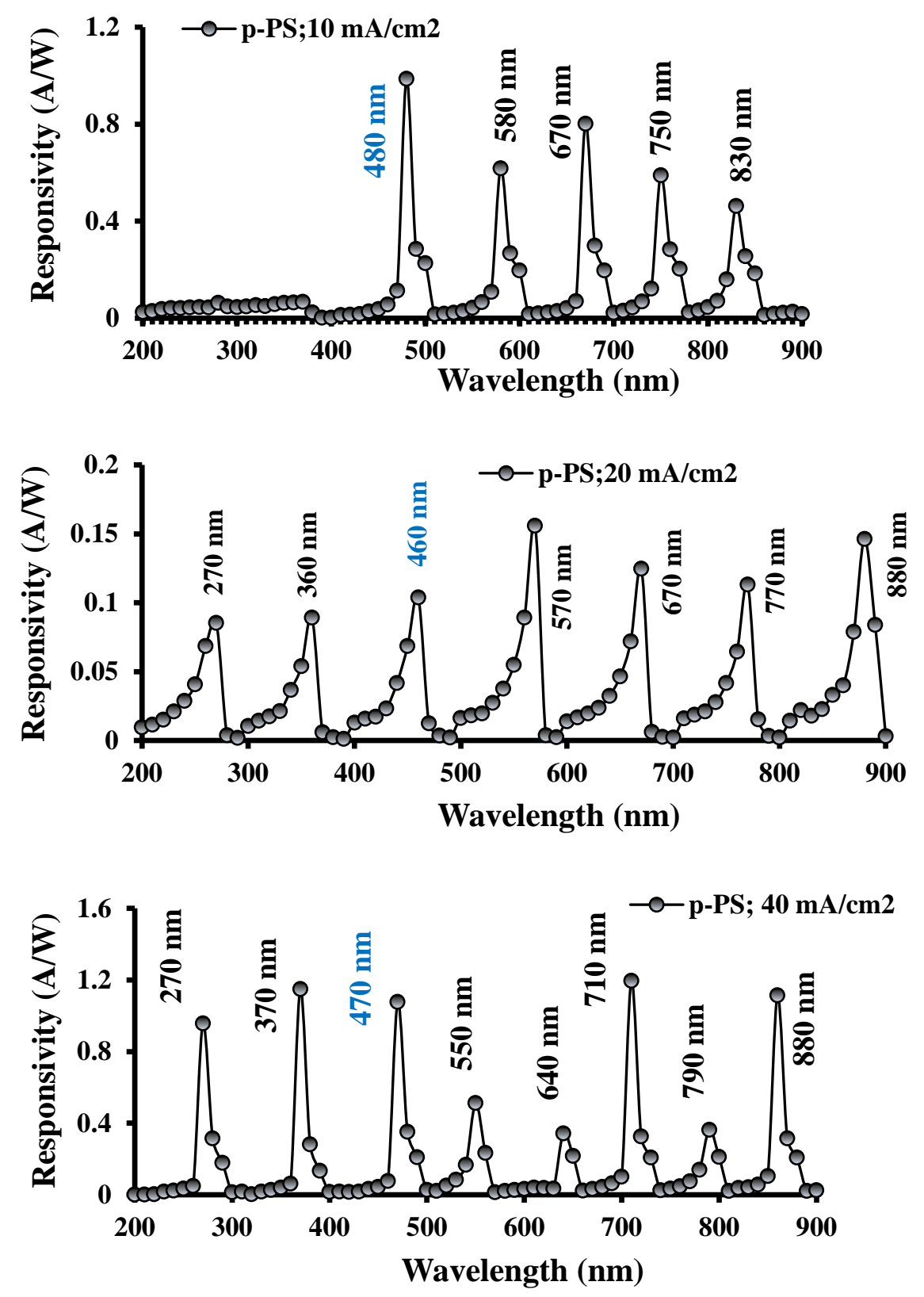

Fig.8: The variation of spectral responsivity of p-PS as a function of the wavelength at different anodization current densities of $(10,20$ and 40$) \mathrm{mA} / \mathrm{cm}^{2}$ at zero bias voltage.

6. The sensitivity - time (S-t) characteristics

The sensitivity-time characteristics are taken at $460 \mathrm{~nm}$ which is in the blue region without bias voltage at different current densities and constant etching time $10 \mathrm{~min}$. When the light was turned on, conductivity increased and after the light was turned off, the current returned to its original value. This process was repeated many times as seen in Fig. 9, one can see the stability of the response with time. From our data, it appears to be possible to control the response of the current in a semiconducting photodetector because the electrons in the nanoparticles receive their excitation energy from the power of the light source, it is possible to "switch" these nanostructures reversibly between higher and lower states of conductivity.

As we see from the figures, the time required around $0.7 \mathrm{~s}$ to travel from its lowest point to its highest and nearly 
from 1 3 second to retreat once the light was turned off. Table 5 shows the sensitivity, rise and fall times in which the sensitivity reaches to maximum value (3797.6 \%) at etching current density $10 \mathrm{~mA} / \mathrm{cm}^{2}$ for blue light. Samples are switched on and off periodically at a regular period of time.
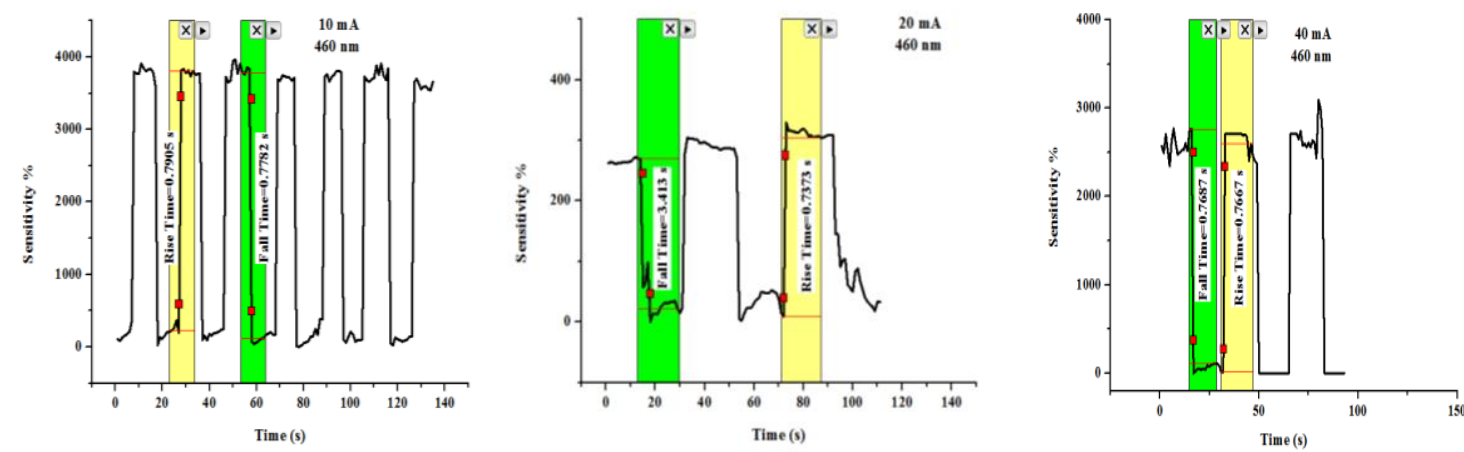

Fig.9: Sensitivity, responsivity, rise and fall times of the p-PS photo sensors under the wavelength of $460 \mathrm{~nm}$ without applied voltage at different etching current densities.

Table5: The sensitivity, rise and fall times values for p-PS with different etching current densities.

\begin{tabular}{|c|c|c|c|c|}
\hline \multirow{2}{*}{$\begin{array}{c}\text { Current } \\
\text { density } \\
\left(\mathrm{mA} / \mathrm{cm}^{2}\right)\end{array}$} & Sensitivity \% at: & $\mathbf{R}_{\lambda}(\mathbf{A} / \mathbf{W})$ & \multirow[b]{2}{*}{$\tau_{\mathbf{r}}(\mathbf{s})$} & \multirow[b]{2}{*}{$\tau_{\mathrm{f}}(\mathbf{s})$} \\
\hline & $460 \mathrm{~nm}$ & $\begin{array}{l}\text { at blue } \\
\text { region }\end{array}$ & & \\
\hline 10 & 3797.6 & 0.987 & 0.7905 & 0.7782 \\
\hline 20 & 257.4 & 0.103 & 0.7373 & 3.413 \\
\hline 40 & 2707.5 & 1.077 & 0.7667 & 0.7687 \\
\hline
\end{tabular}

\section{Conclusions}

It has shown that porous silicon is prepared successfully by electrochemical etching process with spherical pore shape which distributed uniformly within porous layer. The phase of this layer is mixed from $\mathrm{Si}$ and $\mathrm{SiO}_{2}$ which is confirmed by XRD pattern and FTIR analysis. These devices have been used as photo sensor with high sensitivity reaches more than $3000 \%$ for blue light with fast response time less than 1 second without any bias voltage.

\section{References}

[1] D. Wallacher, N. K"unzner, D. Kovalev, N. Knorr, K. Knorr, "Capillary Condensation in Linear Mesopores of Different Shape" Physical Review Letters, 92, 19, (2004) 195704- 195707.
[2] L.T. Canham, Appl. Phys. Lett., 57, 10 (1990) 159-164.

[3] M. Beretta, Ph.D. thesis. University of Milano - Bicocca Department of Materials Science, (2009).

[4] S.K. Mishra, R.K. Srivastava, S.G. Prakash, R.S. Yadav, A.C. Panday, Opto-Electronics Rev., 18, 4 (2010) 467-473.

[5] I.M. Ali, M.S. Raad, T.R. Khalid, M.A. Naser, International Journal of Advanced Research in Science, Engineering and Technology, 1, 5 (2014) 222-227.

[6] N.V. Joshi, Marcel Dekker, New York, (1990).

[7] B.Sayan, K.M.Sheo, S.Biswarup, C.Purushottam, Materials Sciencein Semiconductor Processing, 24 (2014) 200-207.

[8] D.A.Kumar, F.P.Xavier, J.M.Shyla, Archives of Appl. Sci. Res., 4, 5 (2012) 2174-2183. 
[9] M.S. Raad, I.M. Ali, M.Issam, M.Naser, Eng. \& Tech. Journal, 34B, 4 (2016).

[10] S.K.Sharma, H. Gupta, R. Kumar, R.M.Mehra, Turk. J. Phys., 29 (2005) 243-248.

[11] Z. Chen, G. Bosman, R. Ochoa, Appl. Phys. Lett., 62 (1993) 708-710.

[12] K. Hong, C. Lee, J. Korean Physical Society, 42 (2003) 671-675.
[13] U.M. Nayef, M.W. Muayad, International Journal of Basic and Applied Sciences, 13, 2 (2013) 15-17. [14] J.A.S.R.D. Arce, R.R. Koropicki, G. Olmos, A.M. Gennaro, Thin Solid Film., 510 (2006) 169-174.

[15] J. C. Shoou, W.Y. Weng, C.L. Hsueh, T.J. Hsueh, Nano Communication Networks, 1, 4 (2010) 283-288. 